3 Ionic exchange Permeable Reactive Barriers are efficient for the removal of nitrates from

4 polluted soils by EKSF.

\section{Removal of nitrates from spiked clay soils by coupling Electrokinetic and Permeable Reactive Barrier technologies}

6 Manuel A. Rodrigo*

Department of Chemical Engineering, Faculty of Chemical Sciences and Technologies, University of Castilla-La Mancha, Campus Universitario s/n, 13071 Ciudad Real, Spain

*Corresponding author. Tel.: +34 926295300 Ext. 3411; Fax: +34 926295256. 1 E-mail addresses: yoana.garcia.rodriguez@hotmail.com (Y. García), 12 Clara.Ruiz@uclm.es $\quad$ (C. Ruiz), Esperanza.Mena@uclm.es $\quad$ (E. Mena), Jose.Villasenor@uclm.es (J. Villaseñor), Pablo.Canizares@uclm.es (P. Cañizares), 4 Manuel.Rodrigo@uclm.es (M.A. Rodrigo)

\section{Abstract \\ Background}

This work aims to describe the removal of a model anion (nitrate) from clay soils using electrokinetically assisted soil flushing coupled with permeable reactive barriers consisting of beds of anion exchange resin and to assess the influence of the electric field on the efficiency of this technology.

Results

Experiments have been carried out at the bench scale with spiked soil using electric fields ranging from 1.0 to $2.0 \mathrm{~V} \cdot \mathrm{cm}^{-1}$. Results show that removal of nitrates with this remediation technology is very efficient. About $90 \%$ of the nitrates contained in the soil can be removed in less than 1 week of operation with energy consumptions below 75 $\mathrm{kWh} \cdot \mathrm{m}^{-3}$, being worth operating an electric field of $1.2 \mathrm{~V} \cdot \mathrm{cm}^{-1}$ because no improvements are found operating at higher voltage fields. 
There is a great effectiveness of the technology for the removal of nitrates, making 3 it very promising for the removal of anionic pollutants from soils. The main path of 4 change observed is the direction from anode to cathode. Dispersion in the axial direction 5 is very small.

\section{Keywords}

7 Permeable reactive barrier, electrokinetic soil flushing, nitrates, spiked soil, clays

\section{Introduction}

By the early XX century, agriculture underwent a significant revolution due to the commercialization of chemical fertilizers. Chemical fertilizers are based on three principal elements: nitrogen, phosphorous and potassium. Nitrogen is the basis of proteins thus it plays an essential role in plant growth. It can be added to the soil as $\mathrm{NO}_{3}{ }^{-}, \mathrm{NH}_{4}{ }^{+}$ and urea although $\mathrm{NH}_{4}{ }^{+}$and urea are finally oxidized to $\mathrm{NO}_{3}{ }^{-}$by soil microorganisms. Nitrates salts are very soluble, therefore they are leached through soil, being able to reach aquifers or superficial water, also on account of the low capacity of soil particles to adsorb negative species.

Unfortunately, nitrogen base fertilizers are frequently overdosed. The excess of nitrogen species in soil and water media, induces serious problems in plants and animals. In water media it promotes an extreme growth of plants, which causes the eutrophication. Moreover, the intake of nitrates rich water causes health problems for human being, due to the transformation of nitrates into nitrites and then into nitrosamines. Nitrosamines are hazardous species related with some kinds of tumors.

Different technologies for polluted soil remediation are nowadays available, based on thermal, chemical, physicochemical or biological fundamentals. Electrokinetic (EK) soil flushing (EKSF) remediation is especially recommended for the cleaning of low permeability soils where hydrodynamic transport would not be suitable. EKSF remediation is based on the application a direct electric current across electrodes placed in the soil, which produces several transport mechanisms ${ }^{1}$ : electromigration (transport of ions and ionic complexes to the opposite electrodes), electrophoresis (transport of 
1 charged particles to the opposite electrodes, including pollutants bound to mobile

2 particulate matter) and electro-osmosis (movement of ground water to the cathode, caused

3 by superficial charged phenomena). Also different electrochemical reactions, such as

4 electrolysis and electrodeposition occur, and the contaminant migration in soil is

5 simultaneously controlled by mechanisms of sorption, desorption, precipitation and

6 dissolution ${ }^{2}$. EK remediation has been reported to be successful and cost-effective to treat

7 both organic and inorganic contaminants from low-permeability soils, including

8 chlorophenols ${ }^{3}$.

However, EK remediation can include some limitations related to the mobility and solubility of contaminants, control of $\mathrm{pH}$, removal of the accumulated contaminants in the electrode wells, etc. In many cases, using EK remediation alone could not be successful to the required remediation level. Therefore, the technology could be enhanced by coupling with other technologies as part of a global remediation train of processes, supposing that the global proposed process would offer better results than the sum of technologies applied individually ${ }^{4}$.

One of the coupled systems to EK remediation is permeable reactive barriers (PRB). A PRB is an engineered zone of reactive material placed in an aquifer that helps intercepting the pollution plume carried within the aquifer by retaining or degrading the pollutants. The barrier has to be designed to be at least as permeable as the surrounding aquifer material. Usually it is a semi-continuous operation-mode process that needs to replace the PRB material periodically ${ }^{5}$. The subsurface pollution plume can flow through the PRB under natural hydraulic gradients or using pump-and-treat methods. When a PRB is coupled with electrokinetic remediation, the pollutants flow through the barrier is not provided by the advective transport driven by the hydraulic gradient of groundwater, but it is driven by the electro-osmotic flow of soil pore fluid, electromigration or electrophoresis, especially in low permeability soil.

Different materials have been used to build barriers based on several different mechanisms (reduction by using elemental metals, adsorption with porous high-surface materials, ion exchange with resin-based materials, biological degradation, etc) to remove

30 halogenated organics and heavy metals flowing through the PRB. Probably the most 31 extensively material used is granular Zero-Valent Iron (ZVI) which is used as a reductive agent $^{6-9}$. However, other materials are also used. $\mathrm{Weng}^{3}$, and recently Yeung and $\mathrm{Gu}^{4}$ 
1 reported extensive reviews about the current research which couples EK and PRB to

2 remediate soils, including different pollutants and PRB materials. For instance, heavy 3 metals such as $\mathrm{As}, \mathrm{Cr}, \mathrm{Cd}$ and $\mathrm{Ni}$ have been removed from soils by coupling EK/PRB 4 using $\mathrm{ZVI}^{6,7}$, atomizing $\operatorname{slag}^{10}$, carbonized food waste $^{11}$, calcined hydrotalcite ${ }^{12}$ and 5 activated carbon ${ }^{13}$. Suzuki et al. ${ }^{14}$ removed nitrates using ZVI-PRB.

Due to the wide range of ions which can be interchanged, zeolites have been used 7 to perform most of the ion exchange PRBs. $\mathrm{Ca}^{+2}$ rich zeolites have been studied to remove 8 different contaminants from the groundwater such as $\mathrm{Na}^{+15}, \mathrm{Cd}^{+2}{ }^{16}$, and $\mathrm{Cu}^{+2}{ }^{17}$, whereas 9 other zeolites have been used for the removal of hydrocarbons ${ }^{18}$ and $\mathrm{Zn}^{+2}{ }^{19}$ from 10 groundwater. Even a real scale funnel and gate PRB based on the mixture of zeolites and 11 GAC was constructed in Antartica to minimize the environmental damage of a fuel spill ${ }^{20}$. 12 Other ion exchange PRBs made up of anionic and cationic resins have been developed 13 for the treatment of uranium contaminated groundwater. ${ }^{21}$

Regarding the case of nitrates, many authors like Suzuki et al. ${ }^{14}$ reported a review in the case of the EK technology for nitrates removal in soil. In case of PRBs, most of the studies make reference to ZVI iron as the reactive media to remove nitrates from the soil and groundwater 14, 22-24. Biodegradation of nitrates has been also studied using a multispecies biofilm PRB for the treatment of groundwater. ${ }^{25}$

To date, no studies about nitrate removal in soils by EK/PRB coupling have been found. Taking into account it, the authors of the present work considered that it was interesting to study the feasibility of coupling EKSF and ion exchange PRB to remove nitrates from low permeability soils, not only for the potential application but also because nitrates could be used as model of anionic pollutants. In this context, this work aims to describe the removal of nitrates from clay soils using electrokinetically assisted soil flushing coupled with permeable reactive barriers consisting of beds of anion exchange resin and to assess the influence of the electric field on the efficiency of this technology. Because the novelty of the technology presented, results presented in this work, obtained using nitrates polluted soil, can be considered as the starting point for the implementation of the technique for the treatment of another ionic pollutants (e.g., heavy metals).

\subsection{Materials}


Kaolinite was selected as a model for low-permeability soil. This soil is

2 characterized by its inertness, low hydraulic conductivity, lack of organic content and low cation exchange capacity. The properties of the particular synthetic soil used in this study are given in Table 1, according to the data provided by the commercial supplier (Manuel Riesgo Chemical Products, Madrid, Spain).

The chemical selected as pollutant was sodium nitrate. It was of analytical grade and purchased from Panreac Quimica SAU. The polluted soil sample was made by mixing

8 directly a $200 \mathrm{mg} \cdot \mathrm{dm}^{-3} \mathrm{NO}_{3}{ }^{-}$solution $\left(750 \mathrm{~cm}^{3}\right)$ with the kaolinite $(2000 \mathrm{~g})$. The spiked 9 clay was then placed in the experimental setup. A mixture of $1 \mathrm{~g}$ of Purolite A-520E and $500 \mathrm{~g}$ of spiked kaolinite was used as PRB material. Purolite A-520E manufactured by Purolite ${ }^{\circledR}$ (Philadelphia, EEUU) and supplied by Purolite Iberica S.A. (Spain) was used as an anion exchange resin in this study. The Purolite A-520E is a macroporous strong base anion resin which is specially designed for the removal of nitrates from water for potable processes. The macroporous matrix and special ion exchange group functionality imparts ideal nitrate selectivity to Purolite A-520E making this resin particularly suitable for nitrate removal even when moderate to high concentrations of sulfate are present. The original resin was regenerated with two bed volumes of $6 \% \mathrm{NaCl}$ followed by a rinse of four bed volumes of potable water, prior to use. Main characteristics of the Purolite A$520 \mathrm{E}$ are shown in Table 2. Tap water was used as electrolyte and processing fluid in the electrokinetic experiments.

\subsection{EK testing setup}

The bench-scale EK-PRB experiments were performed using the setup shown in Figure 1. The set up consisted of a horizontal methacrylate column with different compartments. It included two electrolyte compartments and reservoirs, using a graphite anode and a titanium cathode $\left(10 \times 10 \mathrm{~cm}^{2}\right.$ each) at the left and right ends compartments (volume of the electrolyte compartments is $10 \times 10 \times 5 \mathrm{~cm}^{3}$; volume of the electrolyte reservoirs is $10 \times 10 \times 10 \mathrm{~cm}^{3}$ ), and a central methacrylate horizontal soil column $\left(10 \times 10 \times 25 \mathrm{~cm}^{3}\right)$ in which the polluted soil was located, except one section which was used as the PRB compartment, closed to the anode compartment $\left(10 \times 10 \times 5 \mathrm{~cm}^{3}\right)$. The setup also contained a direct current power supply and a multimeter. The two sampling points were located in each electrolyte compartments. 
In order to further understand the removal behavior of $\mathrm{NO}_{3}{ }^{-}$by Purolite $\mathrm{A}-520 \mathrm{E}$, aqueous equilibrium anion exchange isotherms $\left(25^{\circ} \mathrm{C}\right)$ were performed through several batch tests using agitated vessels with $1 \mathrm{~g}$ of Purolite A-520E and $100 \mathrm{~mL}$ of increasing concentration solutions (5 to $200 \mathrm{mg} \cdot \mathrm{L}^{-1}$ ) of $\mathrm{NO}_{3}^{-}$until equilibrium was reached, measuring the dissolved $\mathrm{NO}_{3}{ }^{-}$concentration in water.

\subsection{Experimental procedure of EKSF assisted with Purolite-PRB}

The $\mathrm{NO}_{3}{ }^{-}$polluted soil was moistened with the flushing liquid before being located inside the electrokinetic cell. The initial target moisture level for the kaolin was $37.5 \%$. The anode and cathode compartments were filled with the same electrolyte-flushing liquid. Every experiment was then started by applying direct electric current. Three batch experiments, of 7 days duration, were performed, using the applied voltage as the sole variable under study $(15.0,25.0$ and $40.0 \mathrm{~V})$. The electrolyte $\mathrm{pH}$ and conductivity in the anodic and cathodic compartments were measured periodically during the experiments, and the $\mathrm{NO}_{3}{ }^{-}$concentration across the soil column once each experiment was concluded.

\subsection{Sampling and analysis} sampling points. The $\mathrm{NO}_{3}{ }^{-}$content in the soil was determined by the extraction of $1 \mathrm{~g}$ of dry soil with $10 \mathrm{~mL}$ of distillate water. $\mathrm{NO}_{3}{ }^{-}$concentration of the liquid samples was measured by HPLC using a IC I-524 column of an Shimadzu analyzer. pH was measured with a pH-meter GLP-22 (Crison). Electrical conductivity was measured with a GLP-31 conductimeter (Crison).

\section{Results and discussion}

Figure 2 part a shows the changes in the nitrates concentration in the electrodeelectrolyte wells (anolyte and catholyte) during the electro-remediation tests carried out in this work. As it can be observed, nitrates are concentrated in the anolyte wells and they are also transported, although in a much less extension to the catholyte wells. In the first case, electro-migration can easily explain the transport because of the negative ionic 
1 osmotic flow should be the primary mechanism. Increasing and later decreasing of the

2 concentration of the target compound in the catholyte wells suggest the prevalence of the

3 electro-migration mechanisms and that a significant part of the nitrate anions dragged

4 returns to the anolyte wells. Regarding concentration in the anolyte wells, the higher the

5 electric field applied, the higher the concentration reached in electrolyte. This is

6 interesting because, although the purpose of this paper is to study the performance of PRB

7 consisting of ion exchange beds, the flushing and the electromigration are performing

8 well and this fact suggests that other mechanisms, different of the expected ion exchange,

9 are playing an important role and should be accounted.

Figure 2 part $\mathrm{b}$ shows the changes in the $\mathrm{pH}$ in the wells during the three electroremediation tests. As it was expected, $\mathrm{pH}$ of both solutions changes abruptly, as a consequence of the well-known water oxidation (Eq. 1) and water reduction (Eq. 2)

13 processes:

$$
2 \mathrm{H}_{2} \mathrm{O}+2 \mathrm{e}^{-} \rightarrow \mathrm{H}_{2}+2 \mathrm{OH}^{-}
$$

$$
\mathrm{H}_{2} \mathrm{O}-2 \mathrm{e}^{-} \rightarrow 1 / 2 \mathrm{O}_{2}+2 \mathrm{H}^{+}
$$

In this case, due to the low current produced, hydrogen and oxygen are not as important as in other electrolytic processes, but protons and hydroxyl ions produced can influence the results of many of the processes happening during the electro-remediation technology. As observed, from the point of view of $\mathrm{pH}$ steady state is met in less than one day. It is also important to note that steady state values reached depend slightly on the applied electric field and the higher the voltage the higher is the difference between $\mathrm{pH}$ in both wells. An increase in the voltage field produces an increase in the current intensity and also an increase in the rate of the electrokinetic processes (transport of ionic species and electro-osmotic fluxes). The value of the $\mathrm{pH}$ in the wells results from both processes and its increase with voltage field suggests that electrolytic processes are playing a more important role in their value (because they made bigger the difference) than transport processes (which tends to make uniform the differences by transporting protons to the cathode and hydroxyl anions to the anode). 
1 Figure 2 part c shows the changes in the conductivity of the electrolyte contained in the

2 wells during the same electro-remediation tests described before. As it can be observed, 3 this parameter increases in both wells during the progress of the treatment, and these increases can be explained as a result of the two processes studied before, which are:

6 part a.

- Hydroxyl or proton ions electrolytic production as it was discussed in Figure 2 part b.

Increases in the conductivity are higher for the highest electric field test and very similar for the other two tests carried out. Initially, variations in the $\mathrm{pH}$ are expected to 11 be the primary driving force of conductivity changes. However, in Figure 2 it can be 12 clearly observed that dynamic of both processes is very different. Changes in the $\mathrm{pH}$ are 13 much faster than in conductivity. Thus, there are significant changes in the conductivity 14 after the first operation day and obviously they should be related in greater extension to the transport of ions and not only to the hydroxyl or proton ions concentration increase. At this point, it is worth taking into account that ions can be ionically exchanged in the Permeable Reactive Barrier placed next to the anode compartment and that most of the nitrate content of the soil is expected to be retained there at the end of the experiments. These comments help to understand the non-uniform changes in these parameters and even the occurrence of maximums in the conductivity in several of the conductivity timecourses shown.

Regarding electro-osmotic processes, Figure 3 compares the initial moisture of the soil with that obtained at the end of the treatment for one of the tests carried out 24 (intermediate electric field, $25 \mathrm{~V}\left(1.25 \mathrm{~V} \cdot \mathrm{cm}^{-1}\right)$ (specific electric charge passed of 1.68 $25 \mathrm{Ah} \mathrm{kg}^{-1}$ soil)).

As it can be observed, as a consequence of the electro-osmotic fluxes, moisture of the soil increases significantly during the treatment. Most important variations are observed in the regions next to the cathodic wells (due to the primary flow direction) and in the bottom regions of the soil, as a result of the effect of the gravitational fluxes. This increase in the water content of the soil was also observed in many other electro- 
1 remediation tests ${ }^{26,27}$ and it is important from the operation point of view, because it

2 reduces ohmic resistances and prevents the disruption of the ionic circuit in the soil and 3 so, the fail of the electrochemical treatment.

For the same test, Figure 4 shows the amount of nitrates in different portions of the soil after the electrokinetic treatment and compares them with the initial content of nitrates in the soil. As it can be observed, nitrates are efficiently removed from soil using this combined electrokinetic-permeable reactive barrier technology. Every portion was triple measured to prevent analytical mistakes and as it can be observed dispersion is low in spite of being heterogeneous samples.

As expected, because of the electromigration flow and the exchange in the resin, concentrations of nitrates in the PBR are higher. Regarding the high concentration of nitrates in the upper left position of the $4^{\text {th }}$ portion of the soil, it is not easy to find an easy explanation to this local high axial dispersion but this trend was also observed for different positions in the other test carried out in this work and should be explained in terms of the heterogeneity of the soil and the coexistence of many different processes affecting to the nitrate concentrations in very different ways.

Figure 5 part a compares the effect of the electric field on the nitrates remaining in each portion of the soil after the three electrokinetic tests. As it can be observed, removal of nitrates in non-PBR portions is similar after the three tests. The more important and distinctive point seems to be the amount of nitrates concentrated in the PBR soil portion (not fixed on the ionic resin but contained in soil solution) which increases as the electric field decreases (just the opposite trend to that observed in the concentration of nitrates in the anolyte well). As explained before, axial dispersion of data is low (part b) except for the experiment carried out at the lowest voltage field. To better understand this observation, it is worth to compare the effect of the PBR and that of the concentration of nitrates in the electrolyte wells. Thus, Figure 6 compares the ratios of nitrate removed in the PBR and in the complete treatment (electrolyte wells + PBR) as a function of the electric field applied (part a) and also as a function of the electric power dosed to the experimental setup to achieve those conditions (part b).

As it can be observed, the amount of nitrates removed by the ion exchange bed does not seem to depend importantly on the electric field, meaning that from the ionic 
1 exchange point of view, the system should be operating at conditions close to its

2 maximum capacity. However, increases in the electric field attains an enhanced transport

3 of nitrates by electro-migration and hence a higher removal in the anodic wells. Maximum

4 efficiency obtained is close to $90 \%$ and it is important to take into account that the

5 treatment only took 4-5 days. Regarding power consumed, it is clear that it is worth

6 operating an electric field of $1.2 \mathrm{~V} \cdot \mathrm{cm}^{-1}$ because no improvements are found operating at

7 higher voltage fields. Energy consumptions below $75 \mathrm{kWh} \mathrm{m}^{-3}$ are enough to attain a $90 \%$

8 removal operating at these conditions. Empty points show the value obtained after a

9 washing procedure looking for irreversible ion exchange processes. As it can be observed,

10 differences between nitrates obtained by mass balance and recover by a consecutive

11 washing procedure is below $10 \%$ and it seems to be smaller working at higher current

12 densities, because in that conditions removal of nitrates is well complemented by the

13 concentration of nitrates in the anodic well.

A last interesting point is to compare the relation between the amount of nitrate anions retained in the ion exchange resin and the amount expected according to the concentration of nitrates in the solution in contact with the resin (water contained in the soil) and the maximum exchange capacity of the resin. To obtain this relationship, equilibria isotherms of the purolite resin/nitrate system were obtained at the different conditions and also some kinetic data were studied in order to know if the timeline used in the experiments is enough to assure that efficiency of the PBR-EK process is not limited by operation time. As it can be observed in part a of Figure 7, maximum capacity of retention of nitrates is over $100 \mathrm{mg}$ per gram of resin. The total amount of resin in the PRB was 1 gram. Despite the fact that the total amount of nitrates in the soil was $150 \mathrm{mg}$, the irreversibility adsorption in the soil and the electroosmotic flow toward the cathode ensure that the PRB capacity is enough to interchange the nitrates dragged to the bed. Regarding kinetics, steady state is met in less than one hour meaning that timelines used in the electro-remediation test are more than enough to use properly the resin.

The maximum capacity of the resin can be greatly influenced by the matrix and there is a huge change when the resin is in contact with a pure solution of nitrates or enmeshed in a soil matrix. In the soil there are many other anions which could be exchanged in this resin and hence capacity is expected to be lower than that obtained in the lab essay. Figure 8 compares the amount of nitrates retained in the ion exchange bed 
1 according to the mass balance with the expected according to the isotherm taking into

2 account the nitrates contained in the solution. As it can be observed, results are far away

3 from that obtained in pure solutions suggesting that maximum capacity of the resin is

4 greatly influence by its placement in the complex soil matrix and that in spite of having

5 theoretically an excess of resin, its capacity is smaller and it operates in this work at its

6 maximum capacity, as suggested in Figure 7. As a summary of the results previously

7 discussed, Table 3 shows the mass balances of the tests.

\section{Conclusions}

From this work the following conclusions can be drawn:

- Removal of nitrates by electrokinetic soil flushing assisted with ionic exchangepermeable reactive barrier is a very efficient process. About $90 \%$ of the nitrates contained in the soil were removed in less than 1 week of operation with energy consumptions below $75 \mathrm{kWh} \mathrm{m}^{-3}$.

- The two main mechanisms to explain the transport of nitrates are dragging by electro-osmotic flow in cathodic wells and electromigration to anodic wells. The amount of nitrates found in the anodic well increases with the electric field due to electromigration. However, the nitrates interchanged in the PRB are about $60 \%$ in any of the three experiments carried out.

- Despite the great effectiveness of the PRB for the nitrates removal, less than $50 \%$ of capacity was used, due to the heterogeneity of the matrix and the presence of other ions in the system.

- The steady state of $\mathrm{pH}$ in the wells was reached after the first day of operation, whereas conductivity varied slowlier according to the dynamic of the system. Moreover, the moisture increase due to the electroosmotic flow enhanced the electric conductivity of the soil.

- The main path of change is the direction from anode to cathode. Dispersion in the axial direction is very small. The more significant dispersion is found in the PRB at the lowest voltage.

\section{Acknowledgments}


1 The financial support of the Spanish Government through project CTM2010-

218833 is gratefully acknowledged.

\section{References}

1. Virkutyte J, Sillanpää M and Latostenmaa P, Electrokinetic soil remediation Critical overview. Science of the Total Environment 289: 97-121 (2002).

2. Yeung AT, Contaminant extractability by electrokinetics. Environmental Engineering Science 23: 202-224 (2006).

3. Reddy KR and Cameselle C, Electrochemical Remediation Technologies for Polluted Soils, Sediments and Groundwater, pp. 1-732 (2009).

4. Yeung AT and Gu YY, A review on techniques to enhance electrochemical remediation of contaminated soils. Journal of Hazardous Materials 195: 11-29 (2011).

5. Nyer EK, In situ treatment technology. Lewis Publishers, Boca Raton, Fla. (2001).

6. Weng $\mathrm{CH}$, Lin YT, Lin TY and Kao CM, Enhancement of electrokinetic remediation of hyper-Cr(VI) contaminated clay by zero-valent iron. Journal of Hazardous Materials 149: 292-302 (2007).

7. Yuan $\mathrm{C}$ and Chiang TS, The mechanisms of arsenic removal from soil by electrokinetic process coupled with iron permeable reaction barrier. Chemosphere 67: 1533-1542 (2007).

8. Chang $\mathrm{JH}$ and Cheng $\mathrm{SF}$, The remediation performance of a specific electrokinetics integrated with zero-valent metals for perchloroethylene contaminated soils. Journal of Hazardous Materials 131: 153-162 (2006).

9. Choi JH, Choi SJ and Kim YH, Hydrodechlorination of 2,4,6-trichlorophenol for a permeable reactive barrier using zero-valent iron and catalyzed iron. Korean Journal of Chemical Engineering 25: 493-500 (2008).

10. Chung HI and Lee M, A new method for remedial treatment of contaminated clayey soils by electrokinetics coupled with permeable reactive barriers. Electrochimica Acta 52: 3427-3431 (2007).

11. Han JG, Hong KK, Kim YW and Lee JY, Enhanced electrokinetic (E/K) remediation on copper contaminated soil by CFW (carbonized foods waste). Journal of Hazardous Materials 177: 530-538 (2010). 
1 12. Zhang J, Xu Y, Li W, Zhou J, Zhao J, Qian G and Xu ZP, Enhanced remediation of $\mathrm{Cr}(\mathrm{VI})$-contaminated soil by incorporating a calcined-hydrotalcite-based permeable reactive barrier with electrokinetics. Journal of Hazardous Materials 239-240: 128-134 (2012).

13. Saeedi M, Jamshidi A, Shariatmadri N and Falamaki A, An investigation on the efficiency of electro kinetic coupled with carbon active barrier to remediate nickel contaminated Clay. International Journal of Environmental Research 3: 629-636 (2009).

14. Suzuki T, Oyama Y, Moribe M and Niinae M, An electrokinetic/Fe 0 permeable reactive barrier system for the treatment of nitrate-contaminated subsurface soils. Water Research 46: 772-778 (2012).

15. Ganjegunte GK, Vance GF, Gregory RW, Urynowicz MA and Surdam RC, Improving saline - Sodic coalbed natural gas water quality using natural zeolites. Journal of Environmental Quality 40: 57-66 (2011).

16. Ahmed IAM, Young SD and Crout NMJ, Ageing and structural effects on the sorption characteristics of $\mathrm{Cd} 2+$ by clinoptilolite and $\mathrm{Y}$-type zeolite studied using isotope exchange technique. Journal of Hazardous Materials 184: 574-584 (2010).

17. Woinarski AZ, Stevens GW and Snape I, A natural zeolite permeable reactive barrier to treat heavy-metal contaminated waters in Antarctica: Kinetic and fixedbed studies. Process Safety and Environmental Protection 84: 109-116 (2006).

18. Northcott KA, Bacus J, Taya N, Komatsu Y, Perera JM and Stevens GW, Synthesis and characterization of hydrophobic zeolite for the treatment of hydrocarbon contaminated ground water. Journal of Hazardous Materials 183: 434-440 (2010).

19. Lee SH, Jo HY, Yun ST and Lee YJ, Evaluation of factors affecting performance of a zeolitic rock barrier to remove zinc from water. Journal of Hazardous Materials 175: 224-234 (2010).

20. Mumford KA, Rayner JL, Snape I, Stark SC, Stevens GW and Gore DB, Design, installation and preliminary testing of a permeable reactive barrier for diesel fuel remediation at Casey Station, Antarctica. Cold Regions Science and Technology 96: 96-107 (2013). 
1 21. Barton CS, Stewart DI, Morris K and Bryant DE, Performance of three resinbased materials for treating uranium-contaminated groundwater within a PRB. Journal of Hazardous Materials 116: 191-204 (2004).

22. Wang Z, Zhang Z, Li R and Xiao R, Nitrate removal from groundwater using permeable reactive barrier amended with sawdust and zero-valent iron. Nongye Jixie Xuebao/Transactions of the Chinese Society for Agricultural Machinery 44: 112-117 (2013).

23. Tang $\mathrm{C}$, Zhang $\mathrm{Z}$ and Sun $\mathrm{X}$, Effect of common ions on nitrate removal by zerovalent iron from alkaline soil. Journal of Hazardous Materials 231-232: 114-119 (2012).

24. Hosseini SM, Ataie-Ashtiani $B$ and Kholghi M, Bench-scaled nano-Fe 0 permeable reactive barrier for nitrate removal. Ground Water Monitoring and Remediation 31: 82-94 (2011).

25. Tang Y, Zhao H, Marcus AK, Krajmalnik-Brown R and Rittmann BE, A steadystate biofilm model for simultaneous reduction of nitrate and perchlorate, part 2: Parameter optimization and results and discussion. Environmental Science and Technology 46: 1608-1615 (2012).

26. López-Vizcaíno R, Sáez C, Cañizares P and Rodrigo MA, The use of a combined process of surfactant-aided soil washing and coagulation for PAH-contaminated soils treatment. Separation and Purification Technology 88: 46-51 (2012).

27. López-Vizcaíno R, Alonso J, Cañizares P, León MJ, Navarro V, Rodrigo MA and Sáez C, Electroremediation of a natural soil polluted with phenanthrene in a pilot plant. Journal of Hazardous Materials 265: 142-150 (2014). 
Table 1. Properties of soil.

\begin{tabular}{|l|r|l|r|}
\hline \multicolumn{2}{|c|}{ Mineralogy } & \multicolumn{2}{c|}{ Particle size distribution (\%) } \\
\hline Kaolinite & $100.00 \%$ & Gravel & 0.0 \\
\hline $\mathrm{Fe}_{2} \mathrm{O}_{3}$ & $0.58 \%$ & Sand & 4.0 \\
\hline $\mathrm{TiO}_{2}$ & $0.27 \%$ & Silt & 18.0 \\
\hline $\mathrm{CaO}$ & $0.10 \%$ & Clay & 78.0 \\
\hline $\mathrm{K}_{2} \mathrm{O}$ & $0.75 \%$ & Specific gravity & 2.6 \\
\hline $\mathrm{SiO}_{2}$ & $52.35 \%$ & Hydraulic conductivity $(\mathrm{cm} / \mathrm{s})$ & $1 \times 10^{-8}$ \\
\hline $\mathrm{Al}_{2} \mathrm{O}_{3}$ & $34.50 \%$ & Organic content $(\%)$ & 0.0 \\
\hline $\mathrm{Others}^{2}$ & $11.42 \%$ & pH & 4.9 \\
\hline
\end{tabular}

2 
Table 2. Purolite A-520E characteristics.

\begin{tabular}{|c|c|}
\hline \multicolumn{2}{|c|}{ Typical Physical and Chemical Characteristics } \\
\hline Polymer Matrix Structure & Macroporous Styrene-Divinylbenzene \\
\hline Physical Form and Appearance & Opaque Cream Spherical Beads \\
\hline Whole Bead Count & $95 \% \min$. \\
\hline Functional Groups & Quaternary Ammonium \\
\hline Ionic Form, as shipped & $\mathrm{Cl}^{-}$ \\
\hline Shipping Weight (approx.) & $680 \mathrm{~g} \cdot \mathrm{l}^{-1}\left(42.5 \mathrm{lb} \cdot \mathrm{ft}^{-3}\right)$ \\
\hline $\begin{array}{l}\text { Screen Size Range } \\
\text { - U.S. Standard Screen }\end{array}$ & $16-50$ mesh, wet \\
\hline Particle Size Range & $+1200 \mathrm{~mm}<5 \%,-300 \mathrm{~mm}<1 \%$ \\
\hline Moisture Retention, $\mathrm{Cl}^{-}$form & $50-56 \%$ \\
\hline Reversible Swelling $\mathrm{Cl}^{-} \rightarrow \mathrm{SO}_{4}{ }^{2-} / \mathrm{NO}_{3}{ }^{-}$ & Negligible \\
\hline $\begin{array}{l}\text { Total Exchange Capacity, Cl- form, } \\
\text { wet, volumetric } \\
\text { dry, weight }\end{array}$ & $\begin{array}{l}0.9 \mathrm{meq} \cdot \mathrm{ml}^{-1} \mathrm{~min} . \\
2.8 \mathrm{meq} \cdot \mathrm{g}^{-1} \mathrm{~min} .\end{array}$ \\
\hline Operating Temperature, $\mathrm{Cl}^{-}$form & $100^{\circ} \mathrm{C} \max$ \\
\hline pH Range, Stability & $0.0-14.0$ \\
\hline pH Range, operating & $4.5-8.5$ \\
\hline
\end{tabular}




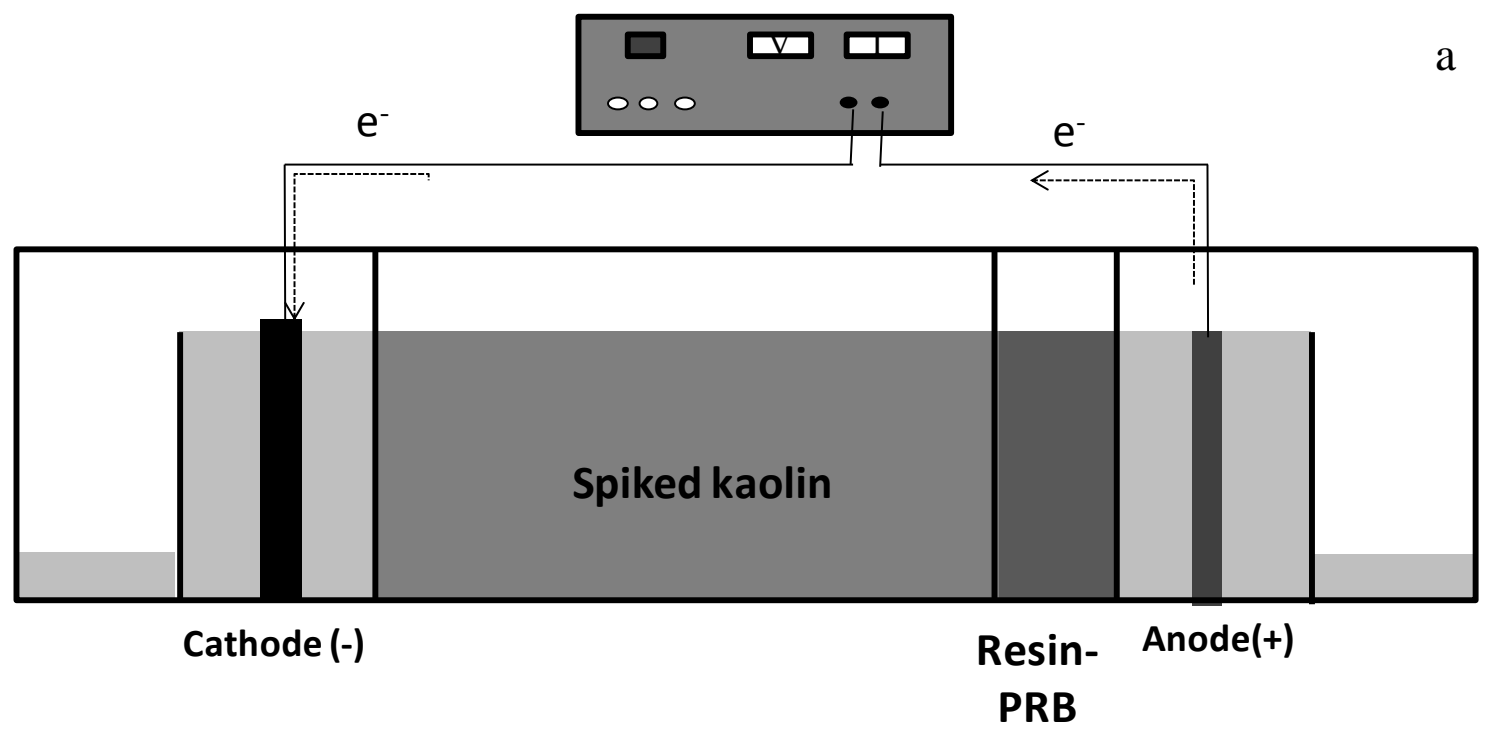

1
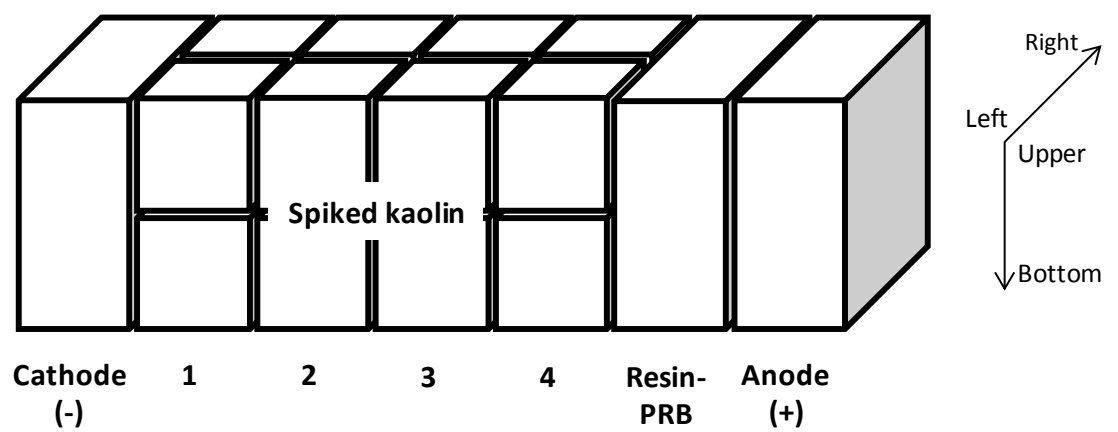

b

2 Figure 1, Part a: Lab scale set-up scheme. Part b: Final sampling points guideline. 

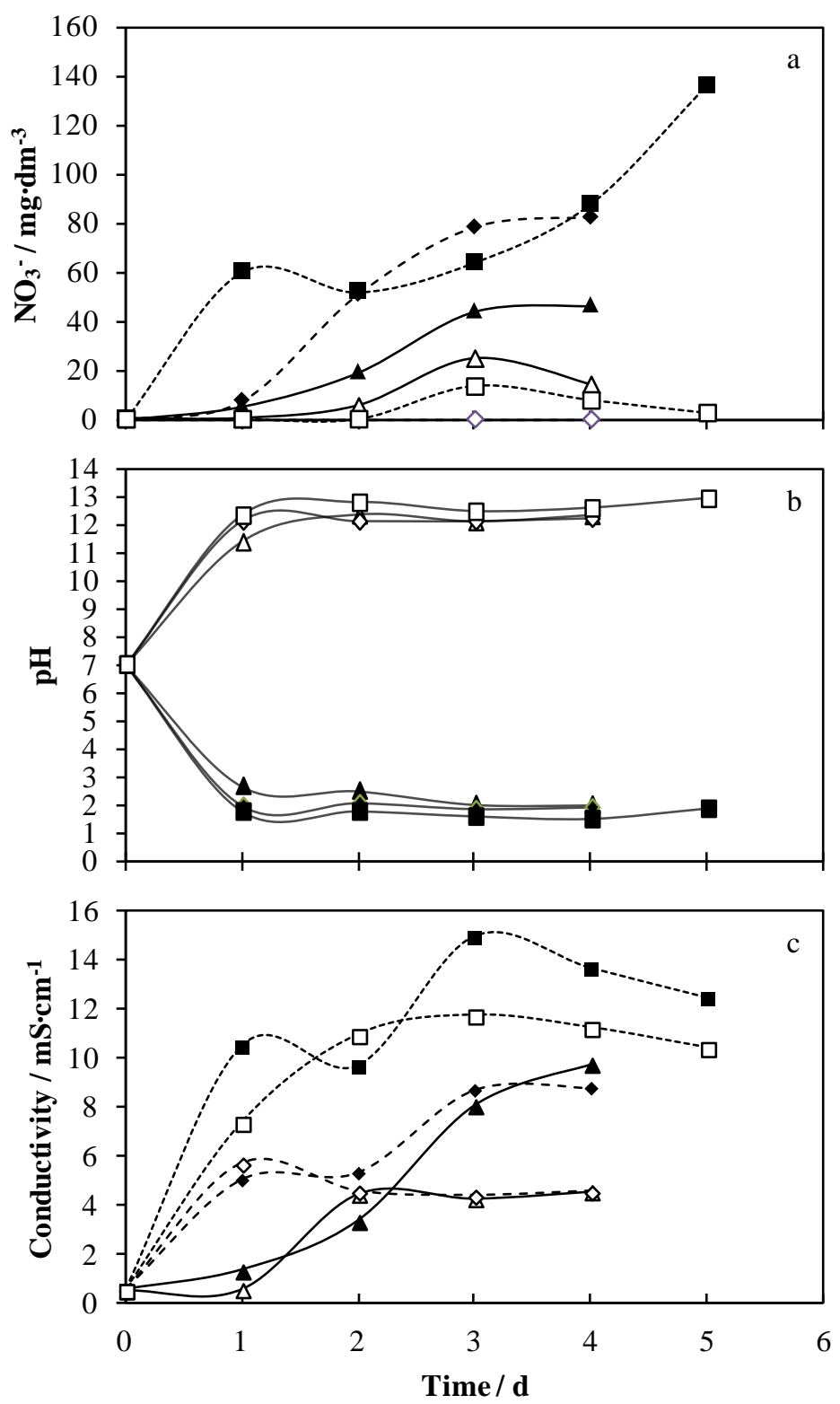

2 Figure 2. Changes in the conditions of the electrolyte in the electrodic wells. Tests at 15.0 $3 \mathrm{~V}$ (triangles), $25.0 \mathrm{~V}$ (diamonds) and 40.0 V (squares). Anodic wells (full symbols) and 4 cathodic wells (empty symbols). Part a: Nitrates concentration. Part b: pH. Part c: 5 Conductivity. 

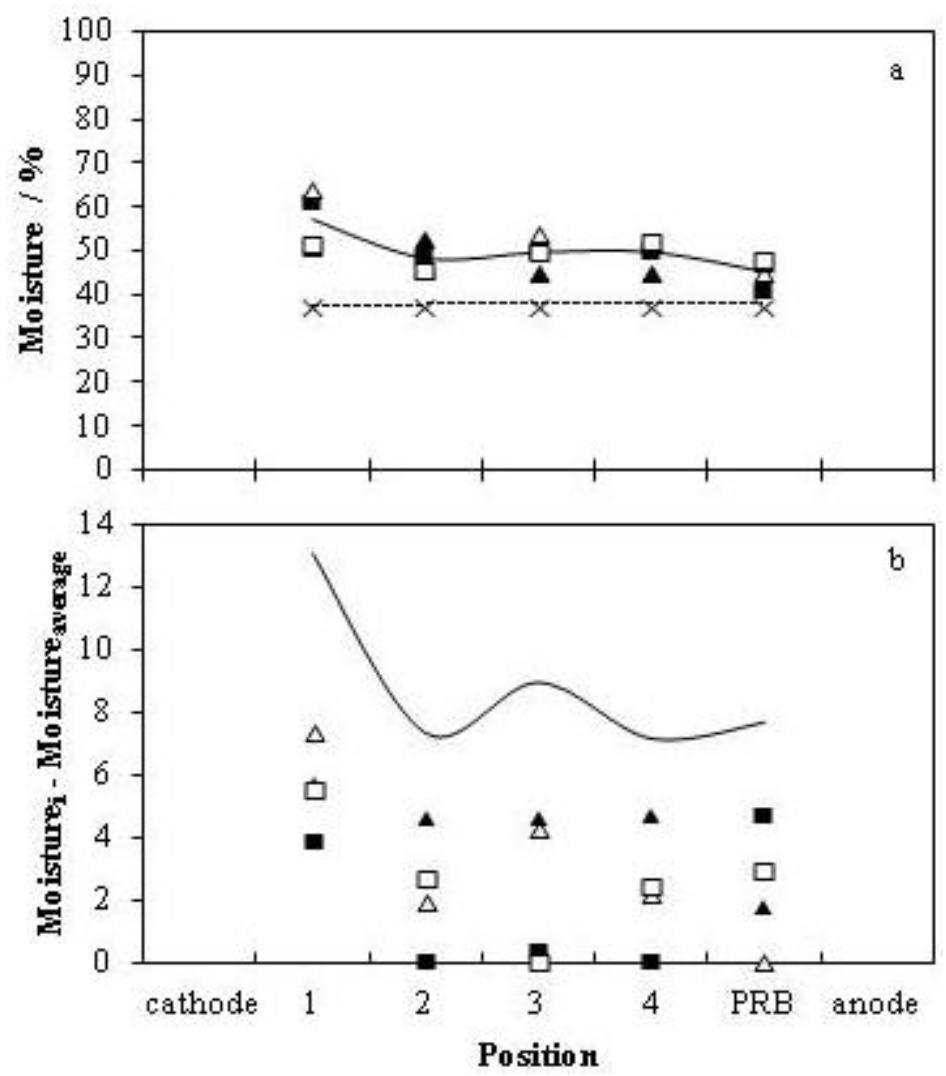

2 Figure 3, Part a: Moisture in the sampling points of the soil. Initial value $(\times)$, final 3 values: upper right point ( $\boldsymbol{\square})$, bottom right point ( $\boldsymbol{\Delta})$, bottom left point $(\square)$, upper left 4 point $(\triangle)$. Average value of the sampling points at the same distance of the electrodes at 5 the end of the test (-). Part b: Difference between punctual and average moisture values 6 at the end of the test, upper right point ( $\boldsymbol{\square})$, bottom right $(\boldsymbol{\Delta})$, bottom left point ( $\square$ ), upper 7 left point $(\triangle)$. Difference between maximum and minimum values $(-)$. 

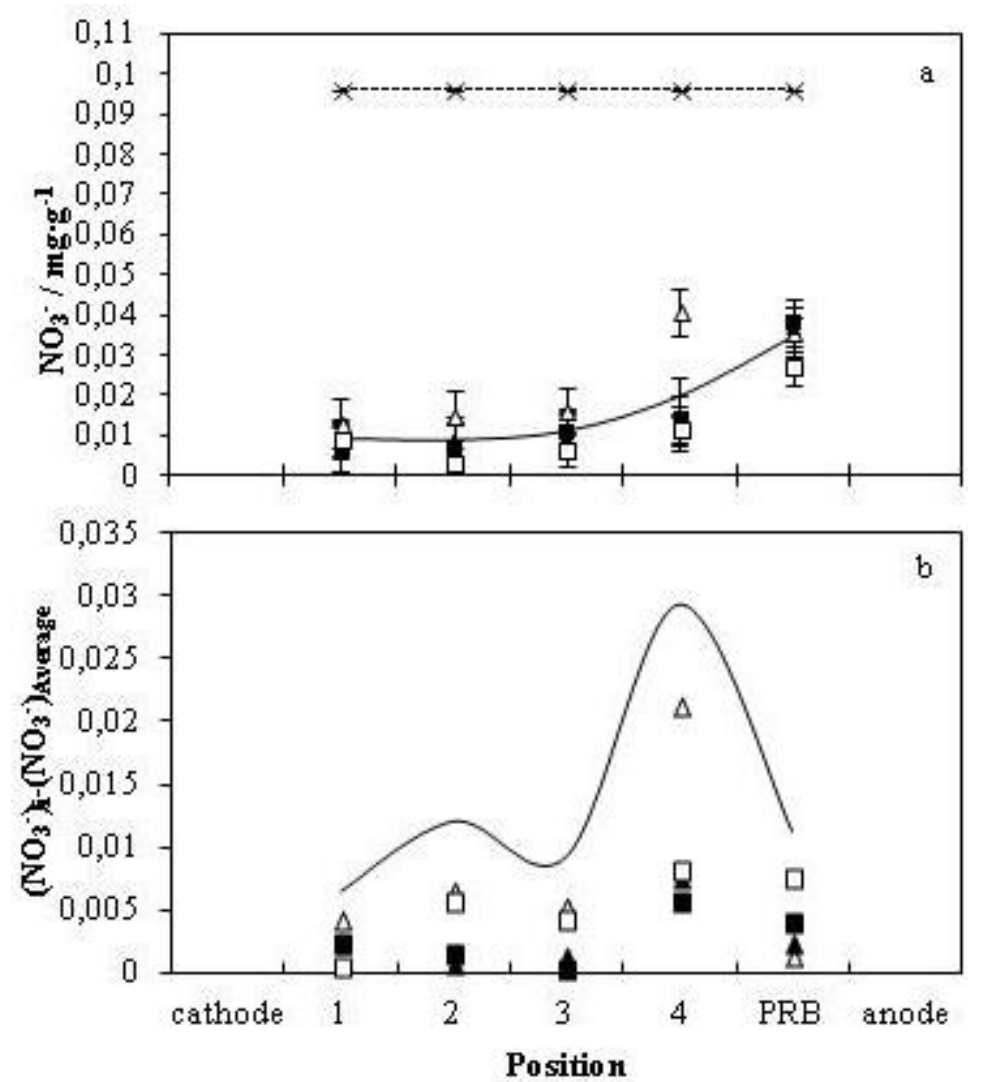

2 Figure 4, Part a: Initial nitrates concentration $(\times)$ and final values in the different 3 sampling points, upper right point ( $\boldsymbol{\square})$, bottom right point $(\boldsymbol{\Delta})$, bottom left $(\square)$, upper 4 left $(\triangle)$, average value of the sampling points at the same distance of the electrodes $(-)$.

5 Bars indicate standard deviation. Part b: Differences between punctual and average 6 nitrates concentration values at the end of the test, upper right point ( $\boldsymbol{\square})$, bottom right 7 point $(\boldsymbol{\Delta})$, bottom left point $(\square)$, upper left point $(\triangle)$, difference between maximum and 8 minimum values $(-)$. 

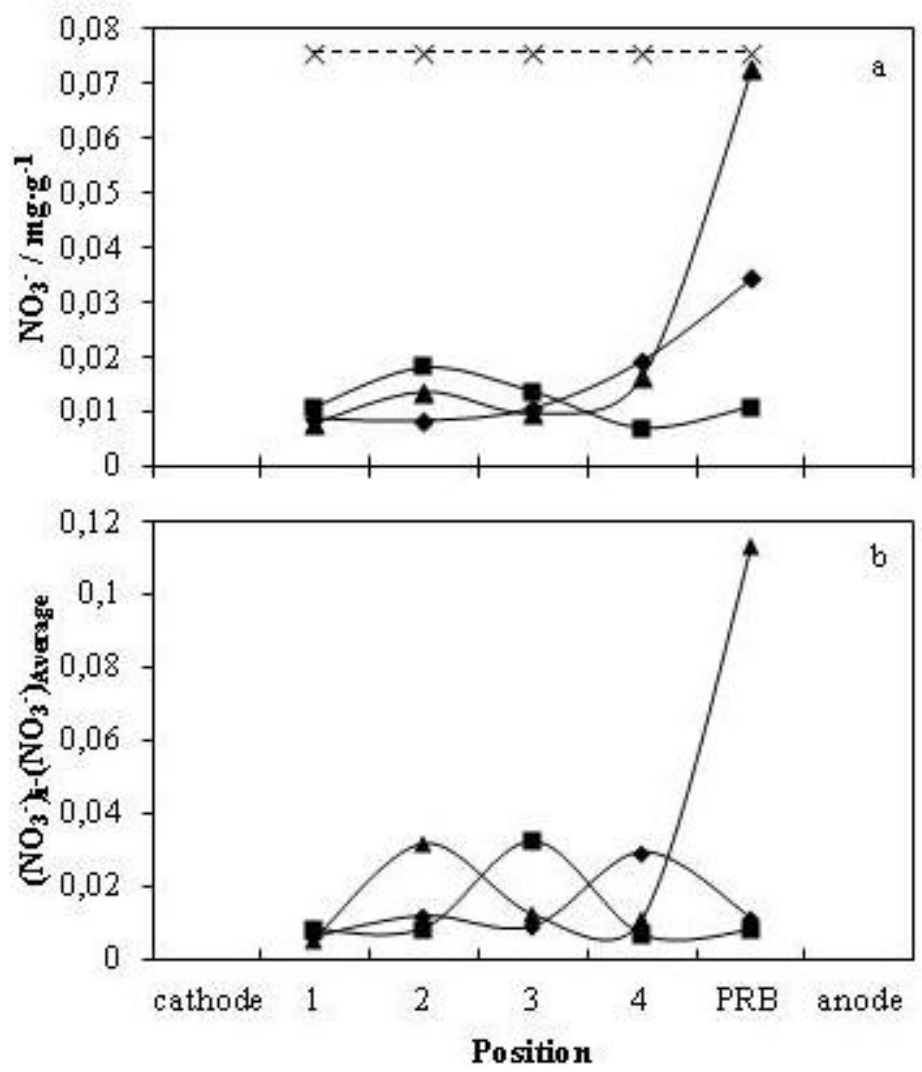

2 Figure 5, Part a: Initial nitrates concentration in the soil $(\times)$ and nitrates concentration 3 remaining in each portion of the soil at the end of the treatment. Part b: Difference 4 between punctual and average values of nitrates concentration at the end of the treatment. 5 Tests at $15.0 \mathrm{~V}(\mathbf{\Delta}), 25.0 \mathrm{~V}(\bullet)$ and $40.0 \mathrm{~V}(\boldsymbol{\square})$. 

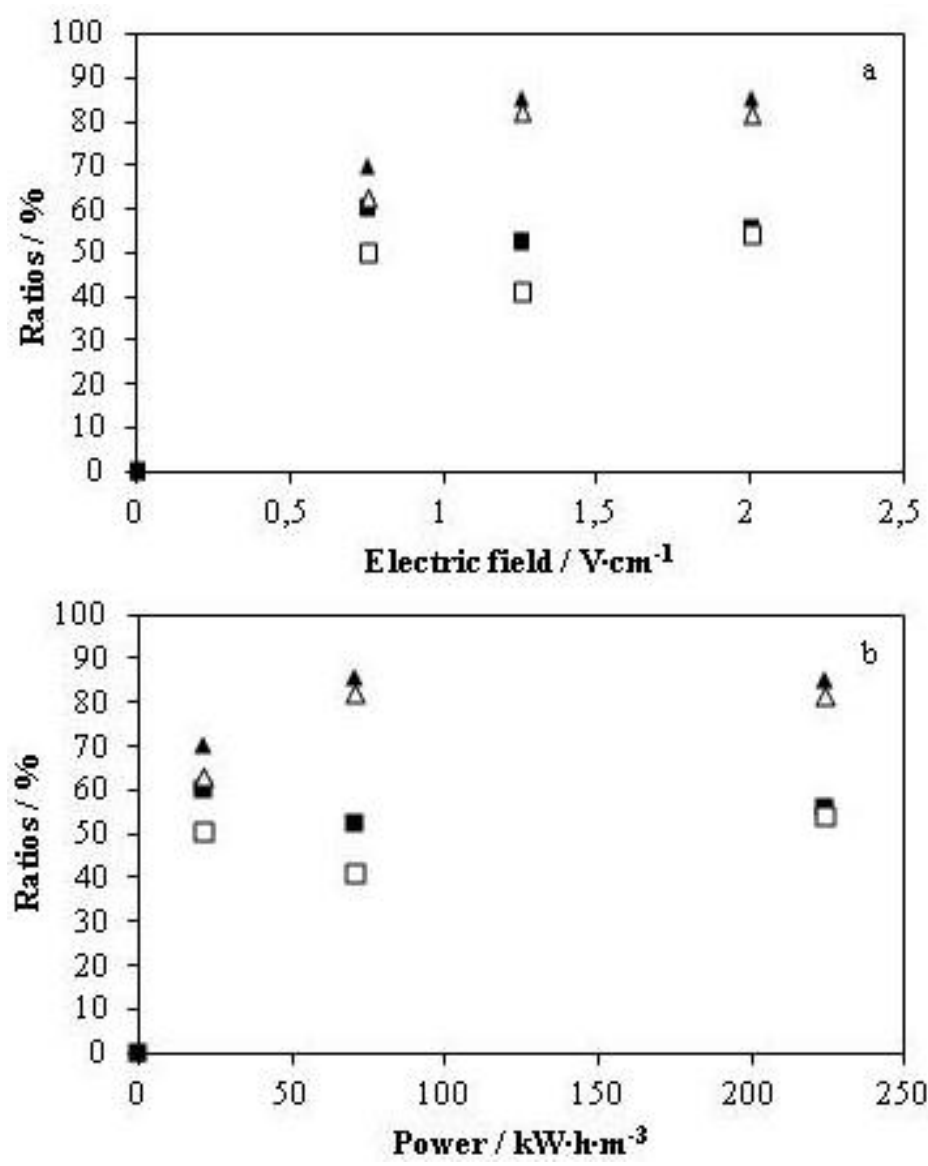

2 Figure 6. Part a: Ratios of nitrate removed in the PBR as a function of the electric field.

3 Part b: Ratios of nitrate removed in the PBR as a function of the electric power. Exchange

4 PRB ( $\square$ ), removal ( $\boldsymbol{\Delta})$, exchange PRB/with irreversibility $(\square)$ and removal/with 5 irreversibility $(\triangle)$.

6 

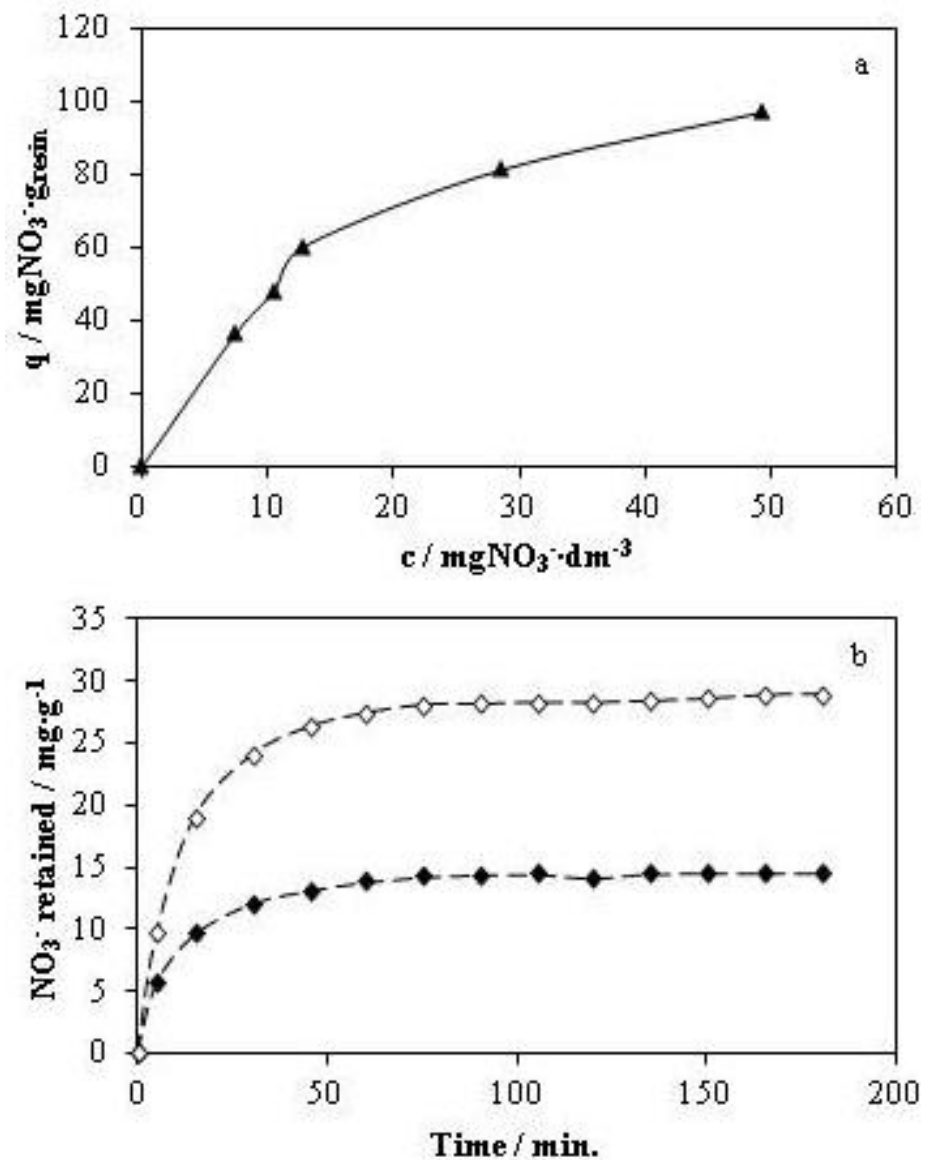

2 Figure 7, Part a: Ionic exchange nitrates purolite capacity. Part b: Kinetic data for the 3 ionic exchange of the purolite resin/nitrate system. Theoretical values (empty symbols) 4 and experimental values (full symbols). 


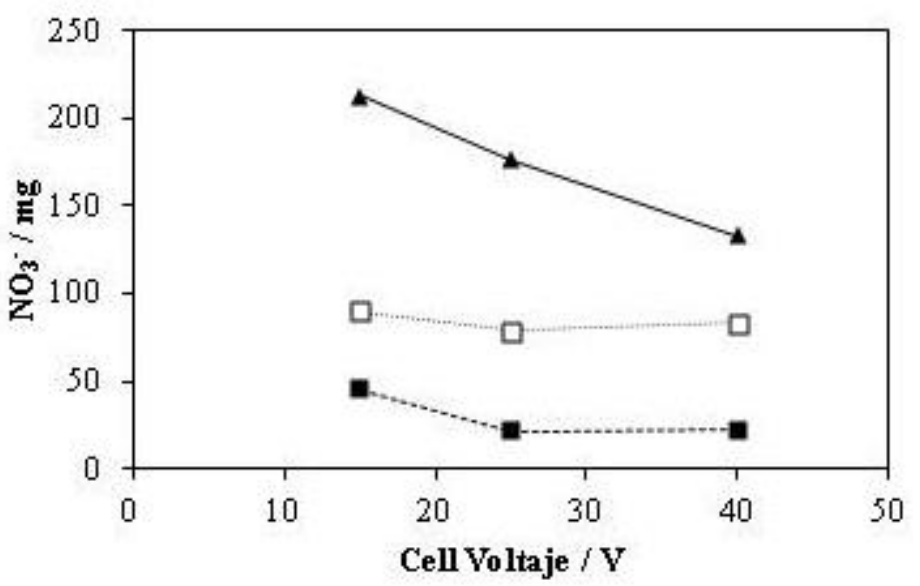

2 Figure 8: Comparison between the amount of nitrated retained in the ion exchange bed 3 and the amount expected according to the isotherm. Amount retained in the soil ( $\square$ ), 4 amount removed according to the mass balance ( $\square$ ), amount theoretically removed 5 according to the capacity of the resin $(\boldsymbol{\Delta})$. 


\begin{tabular}{|l|c|c|c|}
\cline { 2 - 4 } \multicolumn{1}{c|}{} & Exp. 25.0 V & Exp. 15.0 V & Exp. 40.0 V \\
\hline Initial amount of nitrates in the soil (mg) & 150 & 150 & 150 \\
\hline Final amount of nitrates in the soil (mg) & 21.8 & 45.1 & 22.5 \\
\hline Final amount of nitrates in the anolyte (mg) & 26.7 & 15.1 & 44.2 \\
\hline Amount of nitrates irreversibly adsorbed in the soil (mg) & 29.2 & 29.2 & 29.2 \\
\hline Amount of nitrates retained in the PRB (mg) & 72.3 & 60.6 & 54.1 \\
\hline
\end{tabular}

